\title{
The Lipid Lysyl-Phosphatidylglycerol Is Present in Membranes of Rhizobium tropici CIAT899 and Confers Increased Resistance to Polymyxin B Under Acidic Growth Conditions
}

\author{
Christian Sohlenkamp, ${ }^{1}$ Kanaan A. Galindo-Lagunas, ${ }^{1}$ Ziqiang Guan, ${ }^{2}$ Pablo Vinuesa, ${ }^{1}$ Sally Robinson, ${ }^{3}$ \\ Jane Thomas-Oates, ${ }^{3}$ Christian R. H. Raetz, $^{2}$ and Otto Geiger ${ }^{1}$ \\ ${ }^{1}$ Centro de Ciencias Genómicas, Universidad Nacional Autónoma de México, Av. Universidad s/n, Apdo. Postal 565-A, \\ Cuernavaca, Morelos, CP62210, Mexico; ${ }^{2}$ Department of Biochemistry, Duke University Medical Center, Durham, \\ North Carolina 27710, U.S.A.; ${ }^{3}$ Department of Chemistry, University of York, Heslington, York, YO10 5DD, U.K.
}

Submitted 20 March 2007. Accepted 26 June 2007.

Lysyl-phosphatidylglycerol (LPG) is a well-known membrane lipid in several gram-positive bacteria but is almost unheard of in gram-negative bacteria. In Staphylococcus aureus, the gene product of $m p r F$ is responsible for LPG formation. Low pH-inducible genes, termed lpiA, have been identified in the gram-negative $\alpha$-proteobacteria Rhizobium tropici and Sinorhizobium medicae in screens for acid-sensitive mutants and they encode homologs of MprF. An analysis of the sequenced bacterial genomes reveals that genes coding for homologs of MprF from $S$. aureus are present in several classes of organisms throughout the bacterial kingdom. In this study, we show that the expression of IpiA from $R$. tropici in the heterologous hosts Escherichia coli and Sinorhizobium meliloti causes formation of LPG. A wild-type strain of $R$. tropici forms LPG (about 1\% of the total lipids) when the cells are grown in minimal medium at pH 4.5 but not when grown in minimal medium at neutral $\mathrm{pH}$ or in complex tryptone yeast (TY) medium at either pH. LPG biosynthesis does not occur when lpiA is deleted and is restored upon complementation of lpiA-deficient mutants with a functional copy of the lpiA gene. When grown in the low-pH medium, lpiA-deficient rhizobial mutants are over four times more susceptible to the cationic peptide polymyxin $B$ than the wild type.

Rhizobia are soil bacteria able to form a symbiosis with legume plants that leads to the formation of nitrogen-fixing root nodules. Recently it was demonstrated that adequate levels of certain bacterial membrane lipids, e.g., phosphatidylcholine (PC), are also required in order to allow the formation of a fully functional symbiosis between Bradyrhizobium japonicum and its host plant soybean (Minder et al. 2001). It is thought that symbiotic and pathogenic bacteria share similar strategies to avoid responses of the host's immune system (Sohlenkamp et al. 2003). This hypothesis is consistent with the finding that phosphorylcholine epitopes and PC as a membrane lipid are found frequently in prokaryotic organisms closely interacting

Corresponding author: C. Sohlenkamp; E-mail: chsohlen@ccg.unam.mx; Telephone: (+52) 7773-131697; Fax: (+52) 7773-175581.

* The $e$-Xtra logo stands for "electronic extra" and indicates supplemental material is available online. One supplemental figure is published online. with eukaryotic hosts in a symbiotic or pathogenic relationship (Sohlenkamp et al. 2003). Interestingly, Brucella abortus mutants, deficient in the pcs pathway for PC biosynthesis, were shown to lack PC in their membranes and displayed a virulence defect in mice (Comerci et al. 2006; Conde-Alvarez et al. 2006), supporting a role for PC in interactions between symbiotic or pathogenic bacteria and eukaryotic hosts.

Lysyl-phosphatidylglycerol (LPG) is a well-known membrane lipid in several gram-positive bacteria (firmicutes) like Staphylococcus aureus, Bacillus subtilis, and Lactococcus plantarum. The staphylococcal MprF gene product (encoded by the $m p r F / f m t C$ gene) is required for LPG biosynthesis (Oku et al. 2004; Staubitz et al. 2004). In addition to LPG, esters of phosphatidylglycerol (PG) with the amino acids alanine or ornithine have been described in other gram-positive bacteria (O'Leary and Wilkinson 1988). In contrast, in gram-negative bacteria, LPG has only been described in one strain of Pseudomonas aeruginosa (Kenward et al. 1979).

LPG or MprF have been shown to be pathogenicity factors in Staphylococcus aureus, in which they confer on the bacteria a higher level of resistance to cationic peptides of the host's immune system (Peschel et al. 2001). This protective effect of LPG was proposed to be due to its net positive charge. Membranes of $S$. aureus mutants deficient in LPG formation contain only the anionic phospholipids PG and cardiolipin. The presence of LPG, therefore, dramatically changes the charge properties of the membrane surface, thereby interfering with chargebased interactions between cationic antimicrobial peptides and the anionic bacterial surface.

Interestingly, homologs of $m p r F$ from $S$. aureus can be found in the genomes of many other bacteria, most of which are able to interact with eukaryotic hosts as pathogens, symbionts, or commensals (Vinuesa et al. 2003; Fig. S1). This finding implies that LPG might play a role in interactions between bacteria and eukaryotic hosts. For some of the bacteria in which lpiA/mprF homologs are present, e.g., Lactobacillus plantarum, the formation of LPG has been described, whereas for others, such as Agrobacterium tumefaciens, Sinorhizobium meliloti (Geiger et al. 1999), Sinorhizobium medicae (Reeve et al. 2006), or Rhizobium tropici (Rojas-Jiménez et al. 2005), LPG has not been described to form part of the membrane.

During a screen for $R$. tropici mutants deficient in acid tolerance, Vinuesa and associates (2003) have identified the lpiA (low pH-inducible A) gene whose product is homologous to 
MprF from $S$. aureus. In the $R$. tropici genome, the lpiA gene probably forms an operon with atvA (acid tolerance and virulence A). R. tropici mutants deficient in lpiA show a sevenfold reduction in nodulation competitiveness when compared with the wild type (Vinuesa et al. 2003).

Here, we describe the functional characterization of the $R$. tropici lpiA gene. We show that lpiA causes the formation of LPG and that the presence of LPG confers increased resistance to polymyxin. Analysis of the rhizobial $R$. tropici bacteroid membranes shows that LPG might be present in minor amounts.

\section{RESULTS}

\section{mprF/lpiA homologs occur}

in several gram-negative bacteria and form an operon with a gene coding for a putative serine lipase.

LPG and other amino acylesters of PG, such as alanyl-PG (APG) or ornithyl-PG (OPG), have long been known to be major membrane lipids in several firmicutes (O'Leary and Wilkinson 1988), such as S. aureus (LPG) (Nahaie et al. 1984), B. subtilis (LPG) (Op den Kamp et al. 1969), Listeria monocytogenes (LPG) (Fischer and Leopold 1999), Bacillus cereus (APG and OPG) (Houtsmuller and van Deenen 1963; Lang and Lundgren 1970), and Clostridium perfringens (APG) (MacFarlane 1961) but are not generally known as membrane lipids in other classes of bacteria (O'Leary and Wilkinson 1988). However, for one strain of Pseudomonas aeruginosa, Kenward and associates (1979) reported the presence of LPG under certain growth conditions.

Analyses of the sequenced genomes available in public databases reveal that several $l p i A / m p r F$ homologs can be found in organisms outside the firmicutes. Specifically, such homologs can be identified in $\alpha-, \beta-, \gamma-$, and $\delta$-proteobacteria, actinomycetales, planctomycetales, flavobacteriales, and archaea but are absent in eukaryotes. Often $m p r F / l p i A$ homologs occur in bacteria interacting with or closely associated with eukaryotic hosts, be it as symbionts, pathogens, or commensals. However, for some mprF/lpiA homolog-carrying prokaryotes (archaea Methanosarcina barkeri, Bacillus subtilis, Kineococcus radiotolerans, or Lactobacillus plantarum), no such association with a eukaryotic organism has been described. Remarkably, the similarity between MprF/LpiA-like open reading frames from firmicutes and their homologs from other classes of bacteria is restricted to the C-terminal 600 amino acids of the proteins. The identity at the amino-acid level between MprF from $S$. aureus, for which the enzyme activity is known, and the LpiA homolog from $R$. tropici is $28 \%$ for the C-terminal part of the protein (600 of about 850 amino acids).

In most gram-negative organisms whose genomes contain a gene coding for an MprF homolog, this gene forms an operon with a homolog of acvB/atvA/virJ. Such an organization in which $l p i A / m p r F$ and $a t v A / a c v B$ homologs form an operon cannot be observed in gram-positive bacteria (Vinuesa et al. 2003). The $a t v A / a c v B$ genes encode proteins that are homologous to VirJ, a component of the type IV secretion system from Agrobacterium tumefaciens that associates with exported substrates in the periplasm but whose exact function is not known (Pantoja et al. 2002). The type IV secretion system is required for pathogenesis in such gram-negative bacteria as those found in genera Agrobacterium, Bordetella, Brucella, Helicobacter, Legionella, and Rickettsia (Lee and Schneewind 2001).

\section{Expression of $\operatorname{lpiA} / \mathrm{mprF}$ homologs from Bacillus subtilis, Rhizobium tropici, and Staphylococcus aureus in Escherichia coli or in Sinorhizobium meliloti leads to LPG formation.}

Formation of LPG in gram-negative bacteria has only been described for a strain of $P$. aeruginosa (Kenward et al. 1979). However, the one or more genes responsible for LPG formation in gram-negative bacteria have not been identified to date. We suspected that lpiA/mprF homologs of gram-negative bacteria were responsible for LPG formation and, therefore, expressed the lpiA homolog from $R$. tropici, using heterologous overexpression of lpiA under an inducible promoter in E. coli.
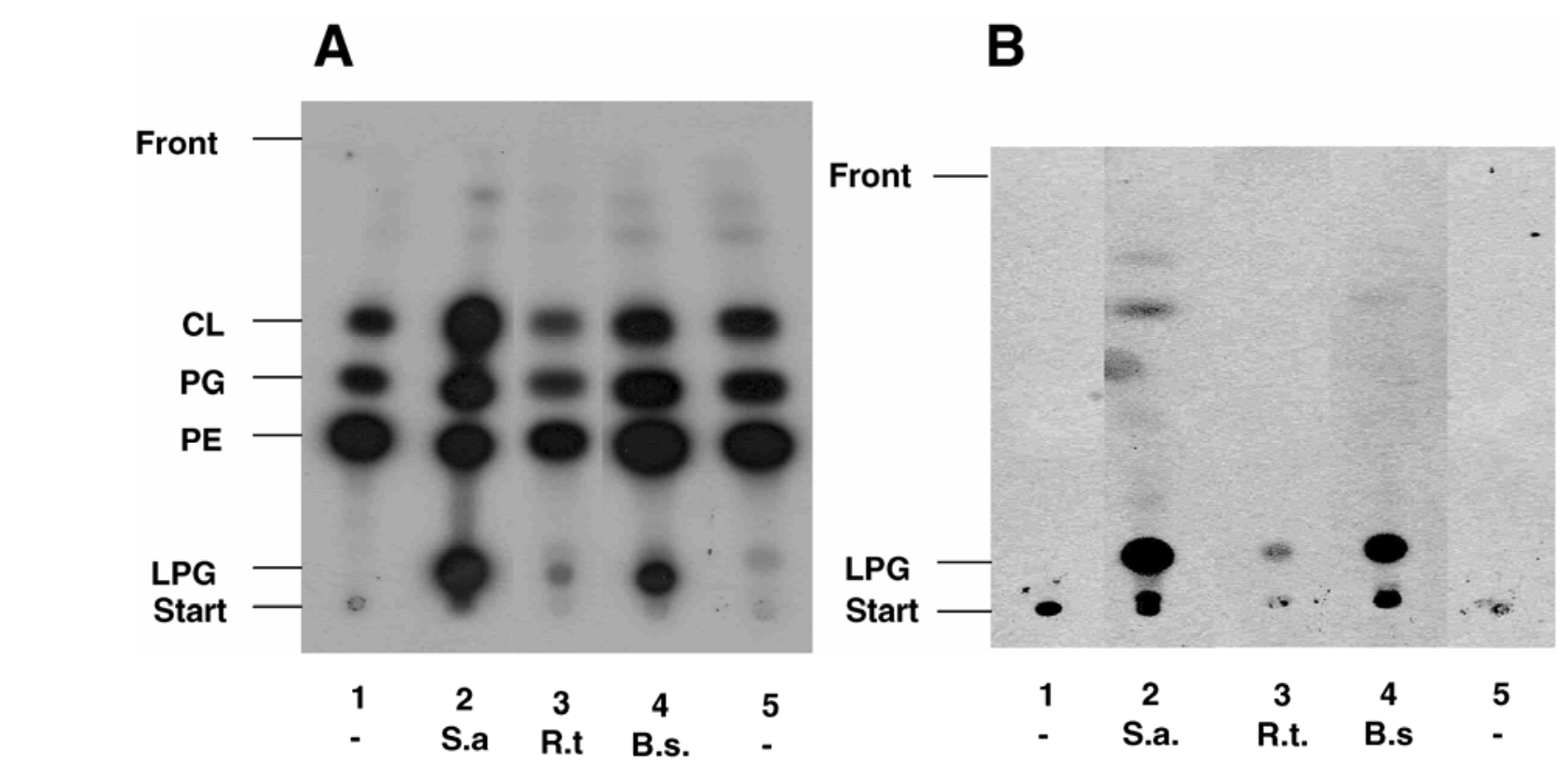

Fig. 1. Expression of MprF/LpiA homologs from Staphylococcus aureus, Rhizobium tropici, and Bacillus subtilis in Escherichia coli. A, Lipids of E. coli BL21(DE3)/pLysS or DH5 $\alpha$ strains containing different plasmids were radiolabeled with $\left[{ }^{32} \mathrm{P}\right]$ phosphate or $\mathbf{B},\left[{ }^{14} \mathrm{C}\right]$ lysine during growth in complex medium and were separated by one-dimensional thin-layer chromatography. The following strains were analyzed: DH5 $\alpha / \mathrm{pBAD} 24$ (lane 1), DH5 $\alpha / \mathrm{pBADmprF}$ (lane 2), BL21(DE3)/pLysS/pCCS49 (lane 3), BL21(DE3)/pLysS/pCCS51 (lane 4), and BL21(DE3)/pLysS/pET16b (lane 5). The organism from which the lpiA/mprF homolog expressed in E. coli were derived are indicated in the figure. $-=$ No lpiA $/ m p r F$ homolog present; S.a. $=S$. aureus mprF; R.t $=$ R. tropici lpiA; B.s. = B. subtilis mprF. The lipids cardiolipin (CL), phosphatidylglycerol (PG), phosphatidylethanolamine (PE), and lysyl-phosphatidylglycerol (LPG) are indicated. 
E. coli does not possess genes homologous to $l p i A / m p r F$ and, therefore, can potentially be used for studying the functionality of $l p i A / m p r F$ gene products. Expression of $S$. aureus $m p r F$ in E. coli DH5 $\alpha$ (Oku et al. 2004) or of the mprF homolog of $B$. subtilis (Reeve et al. 2006) in E. coli BL21(DE3)/pLysS leads to the formation of LPG (Fig. 1) as described in earlier reports. Upon expression of the $R$. tropici lpiA gene in E. coli BL21(DE3)/pLysS, a compound with the same relative mobility as LPG produced by MprF from $S$. aureus or MprF from $B$. subtilis was formed. In contrast, in $E$. coli strains not expressing an lpiA/mprF homolog, only the major membrane lipids phosphatidylethanolamine (PE), PG, and cardiolipin (CL) were observed when the lipids were labeled with $\left[{ }^{32} \mathrm{P}\right]$ phosphate (Fig. 1A) or $\left[{ }^{14} \mathrm{C}\right]$ acetate (data not shown).

Large amounts of LPG were formed when $m p r F$ from $S$. aureus (Fig. 1, lane 2) and $m p r F$ from B. subtilis (Fig. 1, lane 4) were expressed in $E$. coli. In contrast, only a minor amount of a LPG-like compound was formed when lpiA from $R$. trop$i c i$ was expressed in E. coli (Fig. 1A, lane 3). In the case of the expression of $S$. aureus $m p r F$, in addition to LPG formation, a clear change in the relative amounts of PG, CL, and PE was observed (Fig. 1A, lane 2). Apparently, the accumulation of the cationic membrane lipid LPG leads to a relative increase in the anionic membrane lipids PG and CL and a relative decrease in the amount of the zwitterionic PE.

To obtain further evidence for the identity of LPG, we labeled the different $E$. coli strains with $\left[{ }^{14} \mathrm{C}\right]$ lysine. Incorporation of radiolabeled lysine into lipids was observed in E. coli strains expressing either one of the three lpiA/mprF homologs (Fig. 1B, lanes 2, 3, and 4), whereas no lysine incorporation into lipids was observed in the $E$. coli strains carrying empty plasmids (Fig. 1B, lanes 1 and 5).

As LPG formation was not very efficient when lpiA from $R$. tropici was expressed in $E$. coli, we suspected that this inefficient LPG formation might be overcome by expressing lpiA from $R$. tropici in the more closely related bacterium Sinorhizobium meliloti, which has an lpiA/mprF homolog but for which LPG formation has never been described, although its membrane lipid composition has been thoroughly studied in recent years (de Rudder et al. 1999, 2000; Geiger et al. 1999; López-Lara et al. 2003, 2005; Sohlenkamp et al. 2000, 2004).

The $l p i A / m p r F$ homolog from $R$. tropici was subcloned into a broad-host-range plasmid, and the plasmids carrying lpiA from $R$. tropici or $m p r F$ from B. subtilis were mobilized into Sinorhizobium meliloti. Strains were grown in tryptone yeast (TY) medium, lipids were labeled with $\left[{ }^{14} \mathrm{C}\right]$ acetate and were analyzed by two-dimensional thin-layer chromatography (2DTLC). In a Sinorhizobium meliloti strain harboring an empty plasmid, the formation of PC, PE, CL, PG, ornithine-containing lipids, and dimethyl-PE (DMPE) was observed (Fig. 2A). When the lipids from Sinorhizobium meliloti expressing the $m p r F$ homolog from B. subtilis (Fig. 3B) or lpiA from R. tropici (Fig. 2C) were analyzed, the formation of an additional lipid was detected. In both cases, this lipid was ninhydrin-positive and showed a similar mobility to LPG in the 2D-TLC system. To demonstrate that the new lipid is indeed LPG, Sinorhizobium meliloti strains constitutively expressing lpiA from $R$. tropici (1021/pCCS76) or the mprF homolog from B. subtilis (1021/pCCS57) were grown in large cultures and bacterial lipid extracts were analyzed. Using electrospray ionization (ESI)-mass spectrometry (MS) in the positive ion mode, in samples of both lipids, protonated molecules with $\mathrm{m} / \mathrm{z}$ of 903.6 and 877.6 (data not shown) were detected that were absent in the lipid sample extracted from the vector control (1021/pCCS81). Upon collision-induced dissociation of these ions, product ion mass spectra were obtained (Fig. 3A and B) in which, in both cases, ions deriving from the neutral loss of
300.1 Th were observed, corresponding to loss of the lysylglycerophosphate head group from LPG and leading to the formation of the major fragment ions at $m / z 603.5$ and $m / z .577 .5$, respectively. In addition, fragment ions were observed in both spectra at $m / z$ 301.1, corresponding to the protonated lysyl-
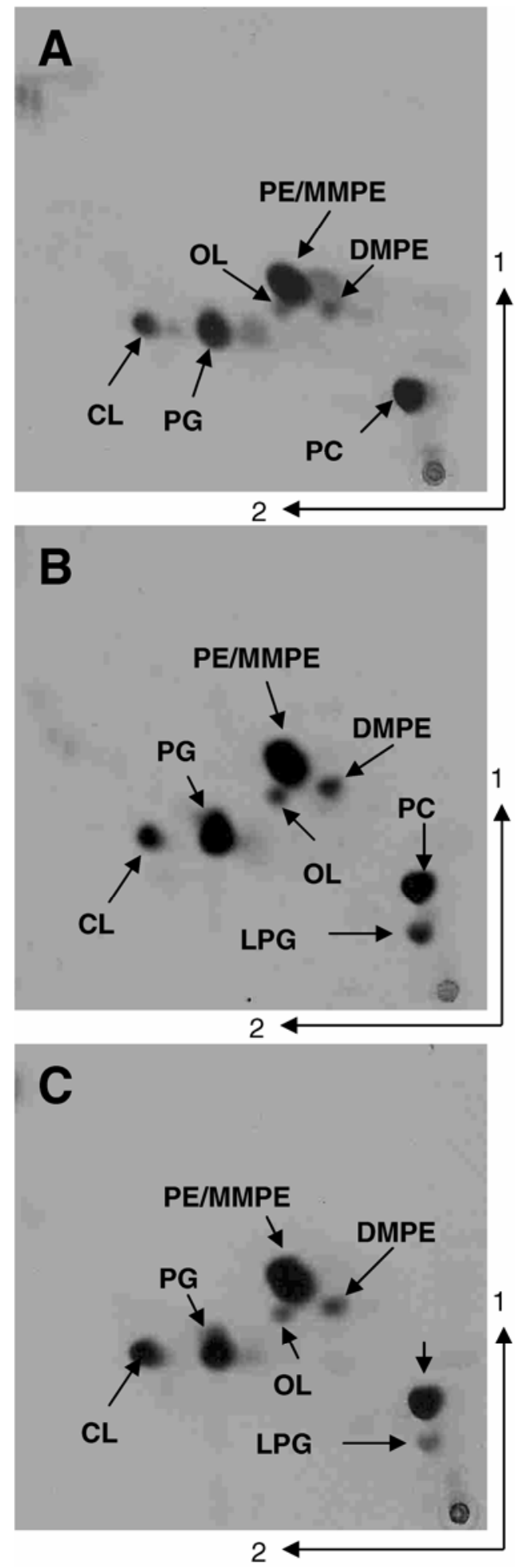

Fig. 2. Separation of $\left[{ }^{14} \mathrm{C}\right]$ acetate-labeled lipids from Sinorhizobium meliloti 1021 harboring A, plasmid pCCS81 (empty), B, pCCS57 (Bacillus subtilis mprF), or C, pCCS76 (Rhizobium tropici lpiA) by two-dimensional thin-layer chromatography. The lipids phosphatidylethanolamine (PE), monomethyl-PE (MMPE), dimethyl-PE (DMPE), ornithine-containing lipid (OL), phosphatidylglycerol (PG), cardiolipin (CL), phosphatidylcholine (PC), and lysyl-phosphatidylglycerol (LPG) are indicated. 

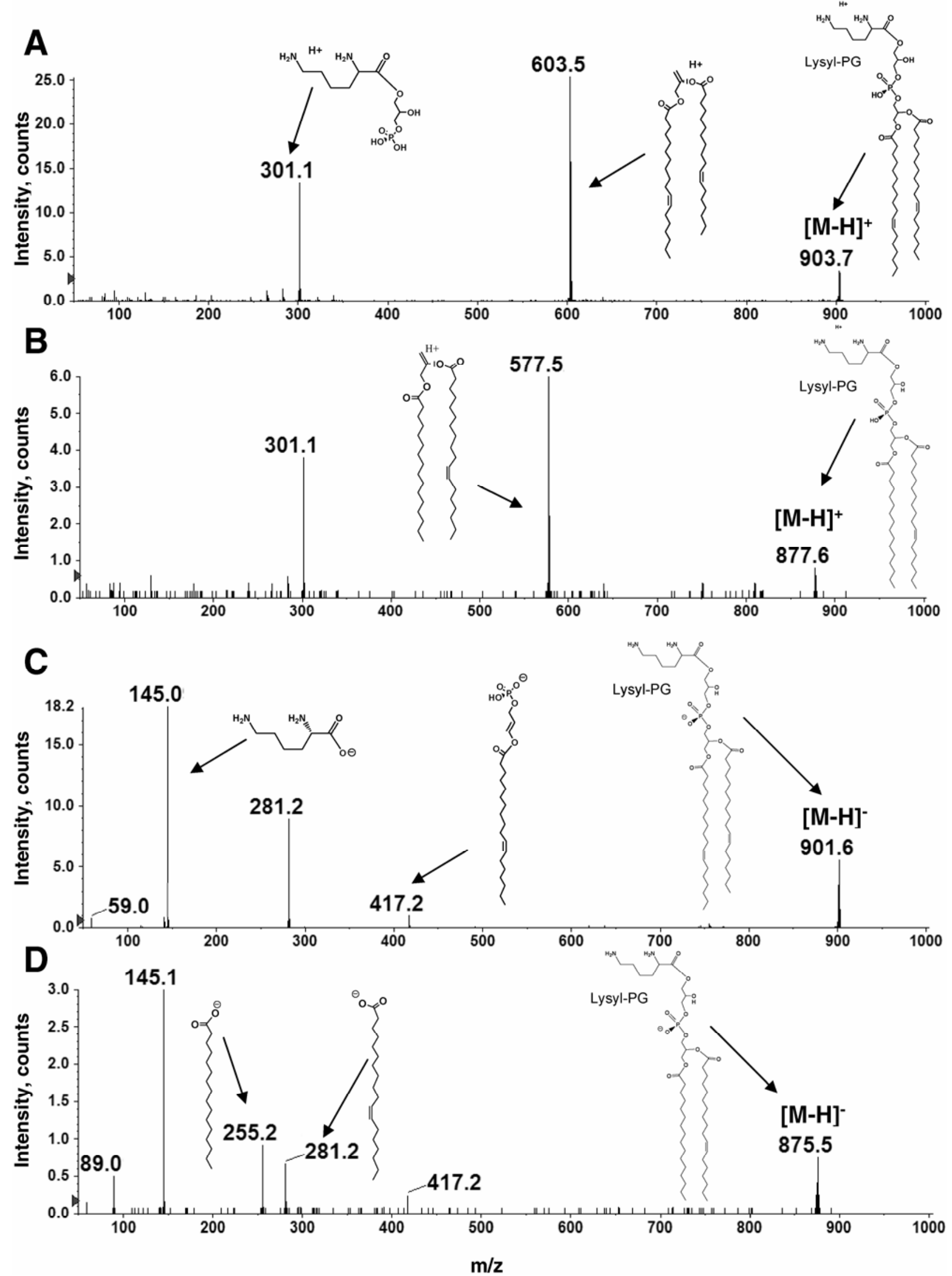

Fig. 3. Collision-induced dissociation mass spectra of lysyl-phosphatidylglycerols detected in lipid extract of Sinorhizobium meliloti constitutively expressing lpiA from Rhizobium tropici. A, and B, Positive ion collision-induced dissociation mass spectra of $[\mathrm{M}+\mathrm{H}]^{+}$ions at $m / z 903.7$ (A) and $877.6(\mathrm{~B})$. C, and $\mathbf{D}$, Negative ion collision-induced dissociation mass spectra of $[\mathrm{M}-\mathrm{H}]^{-}$ions at $\mathrm{m} / \mathrm{z} 901.7$ (C) and 875.6 (D). 
glycerophosphate head group (Fig. 3). In the negative-ion mode, the corresponding ions for deprotonated molecules at $\mathrm{m} / \mathrm{z} 901.6$ and 875.6 were detected, which, upon collisioninduced fragmentation, both yield a product ion at $\mathrm{m} / z$ 145.1, corresponding to deprotonated lysine (Fig. 3). Fragmentation of the ion at $\mathrm{m} / \mathrm{z} 901.6$ yields an intense fragment ion at $\mathrm{m} / \mathrm{z}$ 281.2 (Fig. 3C), corresponding to the C18:1 fatty acyl anion, whereas fragmentation of $\mathrm{m} / z 875.6$ yields fragment ions at both $m / z 281.2$ (C18:1 fatty acyl anion) and at 255.2, corresponding to a C16:0 fatty acyl anion (Fig. 3D). Therefore, when $m p r F$ from B. subtilis or lpiA from R. tropici were expressed in Sinorhizobium meliloti, two major LPG molecules, one bearing two C18:1 fatty acyl residues and another bearing one C16:0 and one C18:1 fatty acyl residue, were identified.

\section{R. tropici CIAT899 wild type forms LPG when grown on minimal medium under acidic conditions.}

When expressing $R$. tropici lpiA in E. coli, formation of LPG was observed, indicating that LpiA is able to catalyze formation of LPG, similarly to what has been described for MprF from $S$. aureus. The lpiA/atvA operon is induced upon acid shock in $\mathrm{Si}$ norhizobium medicae (Reeve et al. 1999, 2006) and $R$. tropici CIAT899 (Vinuesa et al. 2003), and it has been reported that the relative amounts of LPG increase in $S$. aureus and B. subtilis when grown in acidic conditions (Houtsmuller and van Deenen 1964; Op den Kamp et al. 1969). Therefore, $R$. tropici CIAT899 wild type was grown in TY medium adjusted to a $\mathrm{pH}$ of 4.5, 5.5, 6.8 , or 8.0 , and lipids were labeled with $\left[{ }^{14} \mathrm{C}\right]$ acetate. Membrane lipids formed under these growth conditions were the phospholipids PC, PE/monomethyl-PE, DMPE, PG, and CL, and the ornithine-containing lipids S1, S2, P1, and P2 (Rojas-Jimenez et al. 2005). No LPG formation was detected under any of these growth conditions (data not shown).

Kenward and associates (1979) had described LPG formation in one strain of Pseudomonas aeruginosa (NCTC 6750) when grown in a specific minimal medium at neutral $\mathrm{pH}$. Upon growth of $P$. aeruginosa PAO1 (Holloway et al. 1979) under the same conditions as described by Kenward and associates (1979) for NCTC 6750, LPG formation was not observed (data not shown). As the PAO1 genome contains an lpiA/mprF homolog, apparently the regulation of LPG formation must be quite different in these two $P$. aeruginosa strains. A modified version of the minimal medium described by Kenward and associates (1979) was adjusted to $\mathrm{pH} 6.8$ or 4.5 and was used to grow $R$. tropici. In the low $\mathrm{pH}$ medium, formation of a ninhydrin-positive lipid migrating in 2D-TLC like LPG was detected (Fig. 4B) that was not formed when $R$. tropici was grown at neutral pH (Fig. 4A). The relative amount of LPG formed under acidic growth conditions amounted to $1.2 \pm 0.6 \%$ of total lipids. When $R$. tropici wild type was grown in minimal medium at $\mathrm{pH} 4.5$ in the presence of $\left[{ }^{14} \mathrm{C}\right]$ lysine, a preferential incorporation of radiolabeled lysine into LPG (Fig. 4D) was observed, suggesting that this rhizobial lipid formed in minimal medium under acidic conditions contained lysine.

As Kenward and associates (1979) had shown an effect of the magnesium concentration on LPG formation in $P$. aeruginosa NCTC $6750, R$. tropici was grown at two different magnesium concentrations $(1 \mathrm{mM}$ and $8.23 \mu \mathrm{M})$ at neutral or acidic $\mathrm{pH}$. In the case of $R$. tropici CIAT899, no effect of the magnesium concentration on LPG formation was observed (data not shown).

\section{R. tropici CIAT899 mutants deficient in lpiA lack LPG.}

LPG formation was observed when $R$. tropici wild-type CIAT899 was grown at $\mathrm{pH} 4.5$ in the modified minimum medium after Kenward and associates (1979) (Fig. 4B). In contrast, when the lpiA-deficient mutant 899 -lpiA $\Delta l$ was grown at $\mathrm{pH} 4.5$ in such a minimal medium, no LPG formation was ob- served (Fig. 4C), showing that inactivation of lpiA causes a defect in LPG biosynthesis. Upon complementation of $R$. tropici 899-AlpiA1 mutants with the plasmid pCCS76, expressing lpiA from $R$. tropici under the control of a constitutive promoter, formation of LPG was observed (data not shown), demonstrating that the formation of LPG in $R$. tropici depends on a functional copy of lpiA.

\section{$R$. tropici mutants deficient in LPG formation are more susceptible to polymyxin $B$ than the wild type when grown at acidic $\mathbf{p H}$.}

The membrane lipid LPG has been described as a pathogenesis factor in S. aureus (Peschel et al. 2001). S. aureus mutants deficient in LPG formation or with a reduced amount of LPG show increased susceptibility to cationic peptides of the human innate immune response (Peschel et al. 2001) and to the antibiotics moenomycin, vancomycin, and gentamicin (Nishi et al. 2004). Growth of $R$. tropici CIAT899 and the lpiA-deficient mutant was studied on agar containing modified Kenward medium and 20E medium, either one adjusted to $\mathrm{pH} 6.8$ or 4.5, in the presence of various antibiotic-containing filter disks (Oxoid, Hampshire, U.K.). The lpiA-deficient mutant was more sensitive than was the wild type to tobramycin and to polymyxin at $\mathrm{pH} 4.5$, whereas no difference with respect to the susceptibility of the two strains to either antibiotic was observed when the strains were grown at $\mathrm{pH}$ 6.8. The minimal inhibitory concentration (MIC) of polymyxin B was determined for both strains under both growth conditions in liquid media. At neutral $\mathrm{pH}$, the MIC for CIAT899 and the mutant 899-lpiA $\Delta l$ were around 62.5 to 125 and $62.5 \mu \mathrm{g} / \mathrm{ml}$, respectively. When grown at acidic $\mathrm{pH}$, the wild type lost its susceptibility to polymyxin B and showed a MIC of $250 \mu \mathrm{g} / \mathrm{ml}$, whereas the mutant showed a MIC of 31.5 to $62.5 \mu \mathrm{g} / \mathrm{ml}$. We also analyzed the mutant 899-lpiA $\Delta l$ harboring the empty plasmid pCCS81 or the plasmid pCCS76 containing the lpiA gene under control of a constitutive promoter. Surprisingly, the mutant containing the empty plasmid was about four times more sensitive to polymyxin B than the mutant without plasmid. A comparison of the MIC of both plasmid-containing strains showed that the presence of a functional lpiA gene caused a two- to fourfold increase of the MIC when compared with the strain harboring an empty plasmid. At neutral $\mathrm{pH}$, strains lacking and strains containing lpiA showed similar MIC, whereas at $\mathrm{pH} 4.5$, the strains containing lpiA were about four times more resistant to polymyxin $\mathrm{B}$ than the strains lacking lpiA.

\section{Bacteroid membranes of $\boldsymbol{R}$. tropici CIAT899 isolated from bean nodules might contain LPG.}

In the late stages of symbiosis when the bacteroids are engulfed inside the symbiosome inside plant cells, they are exposed to acidic conditions, as the peribacteroid space is about two $\mathrm{pH}$ units more acidic than the plant cytosol (Udvardi and Day 1997; Udvardi et al. 1991). The low pH growth conditions under which $R$. tropici was shown to form LPG therefore, to some extent, mimic the conditions inside symbiosomes. We therefore speculated that the bacteroid membrane might contain LPG. Nodules were harvested from bean plants inoculated with $R$. tropici CIAT899 wild-type bacteria 21 days postinoculation. Bacteroids were isolated as described by Romanov and associates (1994). Lipids were extracted from bacteroids according to Bligh and Dyer (1959). When analyzing the complex mixture of unlabeled bacteroid lipids by liquid chromatography (LC)/MS, signals for protonated molecules at $\mathrm{m} / \mathrm{z}, 903.6$ and 877.6 were observed. Upon collision-induced dissociation of these ions, a fragment was observed at $\mathrm{m} / \mathrm{z} 603.6$ and 577.6, respectively (data not shown). This neutral loss of $300 \mathrm{Th}$ is consistent with loss of the lysylglycerophosphate group, as 
observed on product ion analysis of LPG in the Sinorhizobium meliloti lipid extracts already described (Fig. 3). However, a fragment ion at $m / z 301$ corresponding to the protonated lysylglycerophosphate head group was not observed in this positive ion fragmentation spectrum, nor was a fragment at $\mathrm{m} / \mathrm{z} 145$ (for deprotonated lysine) in the negative-ion product ion spectrum. This is probably due to the small amounts of sample; the bacteroid extracts yielded smaller amounts of overall lipid, and the proportion of LPG in these total extracts was also less than in the Sinorhizobium meliloti mutant lipid extracts expressing lpiA from $R$. tropici. It is not surprising that the only detectable fragment ion was that arising by neutral loss of the headgroup, as this ion was the base peak in the positive ion product ion spectra obtained from the mutant extracts (Fig. 3A and B).

\section{DISCUSSION}

LPG is a well-known lipid in the membrane of gram-positive bacteria like $S$. aureus or B. subtilis but was not thought to be a common membrane lipid in gram-negative bacteria
(O'Leary and Wilkinson 1988). Recently, MprF has been shown to be responsible for LPG formation in S. aureus $(\mathrm{Oku}$ et al. 2004; Staubitz et al. 2004). MprF homologs, called LpiA, have been identified in $R$. tropici and Sinorhizobium medicae in screens for mutants with increased acid sensitivity (Reeve et al. 1999; Vinuesa et al. 2003). Further homologs of $m p r F$ from $S$. aureus can be found in the genomes of bacteria from different phyla, most of which interact as symbionts, pathogens, or commensals with eukaryotic hosts. When we initiated this work, it was not known whether the gene products encoded by $m p r F$ homologs of gram-negative bacteria would catalyze the formation of LPG. The lpiA gene from $R$. tropici was cloned and expressed in the same way as the $m p r F$ homolog from $B$. subtilis, and $m p r F$ from $S$. aureus in a heterologous $E$. coli system (Oku et al. 2004; Reeve et al. 2006). Our data show that the expression of lpiA from $R$. tropici in E. coli leads to the formation of LPG. However, much less LPG is formed in $E$. coli when lpiA from $R$. tropici is expressed as compared with when the $m p r F$ counterparts from the gram-positives $S$. aureus or B. subtilis are expressed. The reason why less LPG

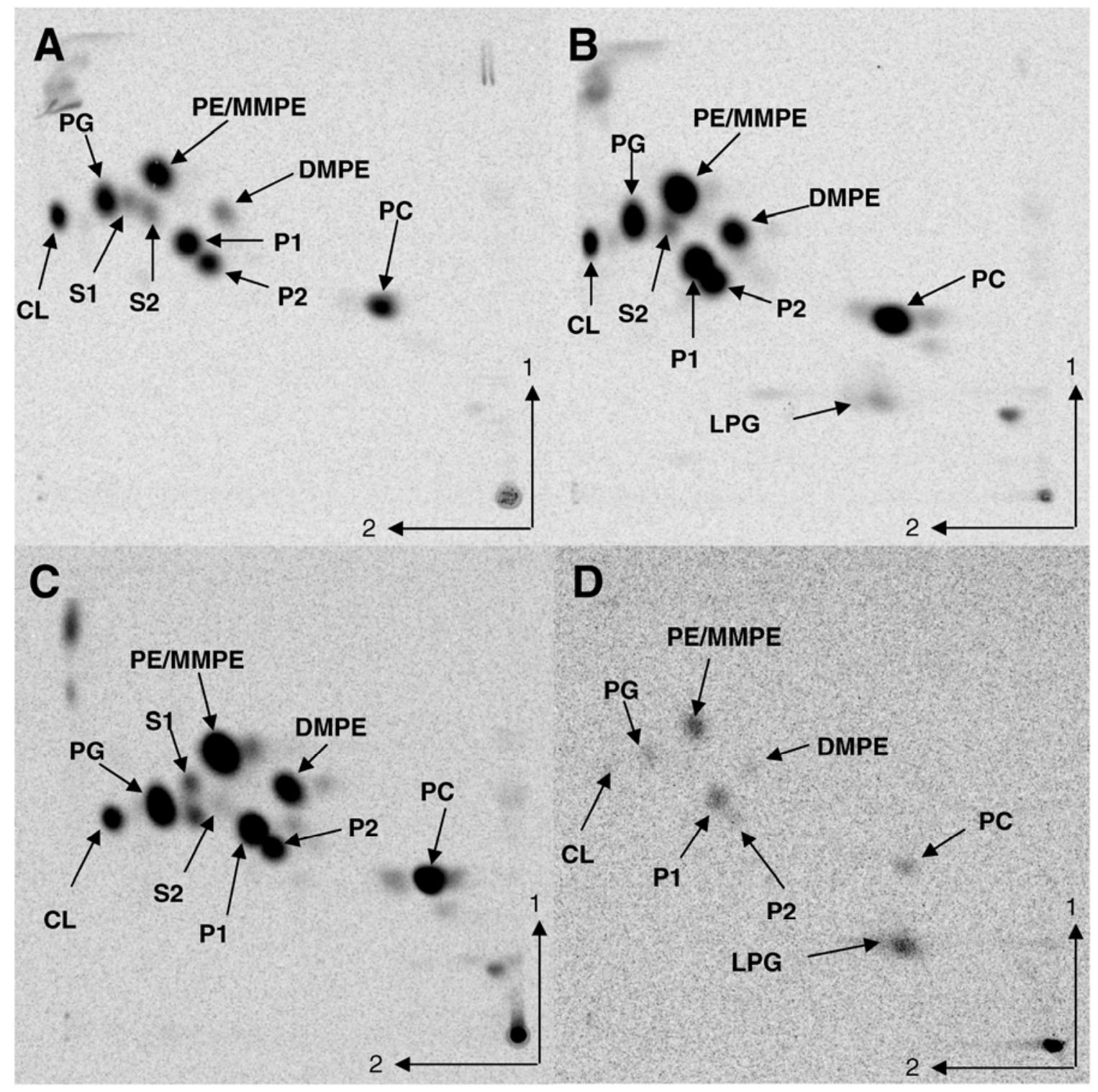

Fig. 4. Lysyl-phosphatidylglycerol formation in Rhizobium tropici CIAT899. A, Cells grown in minimal medium with low magnesium at pH 6.8 or B, C, and D, in minimal medium with low magnesium at $\mathrm{pH}$ 4.5. Separation of $\left[{ }^{14} \mathrm{C}\right]$ acetate- $(\mathrm{A}, \mathrm{B}, \mathrm{C})$ and $\left[{ }^{14} \mathrm{C}\right]$ lysine (D)-labeled lipids from Rhizobium tropici CIAT899 (A, B, D) and $R$. tropici 899-_lpiAl (C). The membrane lipids phosphatidylethanolamine (PE), dimethyl-PE (DMPE), ornithine-containing lipids (S1, S2, P1, P2), phosphatidylcholine (PC), phosphatidylglycerol (PG), cardiolipin (CL), and lysyl-PG (LPG) are indicated. 
is formed upon LpiA expression than upon expression of the gram-positive MprF homologs is not known but might be due to reduced expression of LpiA or to a reduced specific activity of the encoded LpiA enzyme.

We have shown that Rhizobium tropici wild type forms minor amounts of LPG (around 1\% of total lipids) when grown on minimal medium at $\mathrm{pH}$ 4.5. However, LPG formation is not observed when $R$. tropici is cultivated at neutral $\mathrm{pH}$ or on complex TY medium. An lpiA-deficient mutant of $R$. tropici is unable to form LPG on minimal medium at $\mathrm{pH} 4.5$, whereas the mutant complemented with a functional copy of rhizobial lpiA regains the ability to form LPG. Therefore, we report here for the first time on a gene (lpiA) required for LPG formation in gram-negative bacteria.

In $S$. aureus, MprF and LPG have been described as pathogenesis factors. LPG is a major membrane lipid in $S$. aureus comprising 14 to $38 \%$ of total membrane lipids. Absence of LPG in S. aureus leads to a hypersensitivity of the bacteria to cationic peptides of the innate immune response of the human host (Peschel et al. 2001). S. aureus membranes lacking LPG are composed only of the anionic membrane lipids PG and CL. In the model proposed, the strong attraction between the anionic membrane surface of mutant cells and the cationic peptides causes a very high affinity of the peptides for the bacterial membrane of the mutant. However, it is difficult to imagine a model similar to that described for $S$. aureus for rhizobia such as $R$. tropici. The rhizobial membrane lipid composition is more complex than that of $S$. aureus. In $R$. tropici, about $80 \%$ of its membrane lipids are zwitterionic (PE and PC) and only $20 \%$ are anionic lipids (PG and CL) (López-Lara et al. 2003). Therefore, one would not expect that the introduction of $1 \%$ of the cationic membrane lipid LPG would dramatically change the overall charge of the membrane.

Nevertheless, $R$. tropici mutants deficient in LpiA show clear phenotypes. An lpiA-deficient $R$. tropici mutant is sevenfold less competitive than the wild type when nodulating bean; if LPG is present in the bacteroid membrane, it might protect the rhizobia against cationic peptides involved in plant defense (Vinuesa et al. 2003). In support of this idea, we have shown that an lpiA-deficient mutant is several times more sensitive than the wild type to the cationic peptide polymyxin B at low $\mathrm{pH}$. Therefore, although $R$. tropici does not accumulate large amounts of LPG in its membranes, a role for LPG in the interactions with its host is quite possible. However, other explanations than a simple charge-based model need to be considered for the functions of LPG or LPG-derived molecules in gramnegative bacteria.

In contrast to $m p r F$ homologs in gram-positive bacteria, genes encoding for MprF homologs in gram-negative bacteria, such as lpiA in rhizobia are usually encountered in an operon preceding a second gene, atvA (Vinuesa et al. 2003). Often genes in the same operon encode proteins that interact or that act in the same metabolic pathway (Dandekar et al. 1998; Overbeek et al. 1999). The levels of LPG in gram-negative bacterial membranes are low, and AtvA might contribute to a low steady-state level of LPG by degrading it, for example, by acting on it as a lipase. Such a lipase activity efficiently degrading LPG might be an explanation why accumulation of LPG has not been described in gram-negative bacteria, although several well-studied gram-negative bacteria have lpiA/mprF homologs in their genomes.

If LPG indeed protects gram-negative bacteria against cationic peptides, this protection could only be conferred by a more specific mechanism. The anionic membrane lipid CL has been described to form domains in bacterial membranes (Kawai et al. 2004). Such anionic membrane domains could be targets for cationic peptides that have penetrated beyond the outer membrane. The presence of LPG might interfere with the formation of such domains, or it might neutralize the negative charge of the membrane surface to some extent. The different cell-wall structures of gram-positive and gram-negative bacteria also have to be taken into account. The model described for the MprF-mediated protection of the gram-positive bacteria against cationic peptides would have to be modified in the case of gram-negative bacteria due to the presence of the outer membrane. Gram-negative bacteria such as E. coli, P. aeruginosa, and Salmonella typhimurium have been shown to modify their lipid A structures as a protective mechanism against cationic peptides (Raetz and Whitfield 2002). No other modifications of the lipidic parts of the inner or outer membranes are known that are related to resistance of the bacteria against cationic peptides.

The low $\mathrm{pH}$ conditions under which LPG is formed mimic the conditions that $R$. tropici encounters inside nodules. We have, therefore, investigated whether LPG might be present in membranes obtained from the symbiotic bacteroid form. Mass spectrometric results suggest that small amounts of LPG might indeed be present in bacteroid membranes.

\section{MATERIALS AND METHODS}

\section{Bacterial strains, media and growth conditions.}

The bacterial strains and plasmids used and their relevant characteristics are shown in Table 1. Rhizobium tropici and Sinorhizobium meliloti strains were grown at $30^{\circ} \mathrm{C}$ in complex TY medium containing $4.5 \mathrm{mM} \mathrm{CaCl}_{2}$ (Beringer 1974). $R$. tropici was also grown in a modified version of the minimal medium described by Kenward and associates (1979) or in 20E medium (Werner et al. 1975). The modified Kenward medium used for growth of $R$. tropici contained $39.04 \mathrm{mM}$ $\left(\mathrm{NH}_{4}\right)_{2} \mathrm{HPO}_{4}, 0.96 \mathrm{mM}\left(\mathrm{NH}_{4}\right) \mathrm{H}_{2} \mathrm{PO}_{4}, 0.2 \mathrm{mM}\left(\mathrm{NH}_{4}\right)_{2} \mathrm{SO}_{4}, 1.0$ $\mathrm{mM} \mathrm{NaCl}, 1.0 \mathrm{mM} \mathrm{KCl}, 8.95 \mu \mathrm{M} \mathrm{FeSO}_{4}, 164.5 \mu \mathrm{M} \mathrm{CaCl}_{2}, 12$ $\mathrm{mM}$ glucose, and either $1 \mathrm{mM}$ or $8.23 \mu \mathrm{M} \mathrm{MgSO}$. Vitamins (biotin, $0.2 \mathrm{mg} / \mathrm{ml}$; calcium pantothenate, 0.1, thiamine, 0.1 ) were added to the final concentrations indicated. The $\mathrm{pH}$ of the medium was adjusted to 6.8 using $40 \mathrm{mM}$ HEPES (N-[hydroxyethyl]piperazine- $\mathrm{N}^{\prime}$-[2-ethanesulfonic acid]) or to 4.5 by using $20 \mathrm{mM}$ HOMO-PIPES (homopiperazine-N,N'-bis-2ethanesulfonic acid).

For determination of the MIC of polymyxin B (Sigma, St. Louis), wild-type CIAT899 and the lpiA-deficient mutant 899lpiA $\Delta 1$ were cultivated in 20E medium (Werner et al. 1975), adjusted to pH 6.8 (20E, 6.8) using $40 \mathrm{mM}$ HEPES (Sigma) or to $\mathrm{pH} 4.5(20 \mathrm{E}, 4.5)$ using $50 \mathrm{mM}$ HOMO-PIPES (Research Organics, Cleveland, OH, U.S.A.). R. tropici strains were grown for 3 days on TY medium agar plates. Precultures inoculated from cells grown on solid media were cultivated overnight in liquid 20E, 6.8 medium. Using aliquots of these preculture cultures of 20E, 4.5 and 20E, 6.8 medium were inoculated and grown for a further $24 \mathrm{~h}$. Cultures were diluted in $20 \mathrm{E}$ medium adjusted to the respective $\mathrm{pH}$ to approximately $2 \times 10^{5}$ $\mathrm{CFU} / \mathrm{ml}$, and $1 \mathrm{ml}$ of these cultures was mixed with $1 \mathrm{ml}$ polymyxin solution (dissolved in 20E) at concentrations between 1 $\mathrm{mg} / \mathrm{ml}$ and $2 \mu \mathrm{g} / \mathrm{ml}$. Cultures were incubated for $96 \mathrm{~h}$, and optical densities were determined at 48, 72, and $96 \mathrm{~h}$. MIC was taken as the lowest concentration of polymyxin B that reduced growth by more than $90 \%$. When plasmid-harboring strains were analyzed, we observed that the presence of gentamicin used to select for the presence of the plasmids was interfering with the determination of the MIC. Therefore, gentamicin was omitted in the precultures at the specific $\mathrm{pH}$ and in the cultures in which polymyxin B was present.

Escherichia coli strains were cultured on Luria-Bertani (LB) medium at $37^{\circ} \mathrm{C}$. Antibiotics were added to the medium at the 
following final concentrations when required $\left(\mu \mathrm{g} \mathrm{ml}{ }^{-1}\right): 70$, gentamicin for Sinorhizobium meliloti; 100, carbenicillin; 10, gentamicin; and 20, chloramphenicol for E. coli.

Plasmids were mobilized into $R$. tropici and Sinorhizobium meliloti strains by triparental mating using the mobilizing plasmid pRK2013 as described previously (Ruvkun and Ausubel 1984).

\section{DNA manipulations.}

Recombinant DNA techniques were performed according to standard protocols (Sambrook and Russell 2001), using Escherichia coli DH5 $\alpha$ as a host strain (Hanahan 1983).

\section{Cloning of the lpiA gene of $R$. tropici}

\section{for complementation and expression studies.}

The $R$. tropici lpiA coding sequence was polymerase chain reaction (PCR)-amplified using the XL PCR kit (Rtrop_lpiA5: 5'-AcgTCATATgTCgagCCCAATCgATCTggAAAg-3'; Rtrop_ lpiA3: 5'-ACgTggATCCTCATTTCCTCACgACCCCCTTAAg TC-3'; Applied Biosystems, Foster City, CA, U.S.A.) introducing NdeI/KpnI restriction sites. The PCR product was cloned into pCR-Blunt II-TOPO (Invitrogen, Carlsbad, CA, U.S.A.). The resulting plasmid was digested with the corresponding enzymes to liberate the coding sequence, and the $R$. tropici lpiA gene was cloned as an NdeI/KpnI fragment into plasmid pET17b to obtain pCCS49. The mprF homolog from Bacillus

Table 1. Bacterial strains and plasmids used in this study

\begin{tabular}{|c|c|c|}
\hline Strain or plasmid & Relevant characteristics $^{\text {a }}$ & Reference \\
\hline \multicolumn{3}{|l|}{ Rhizobium tropici } \\
\hline CIAT899 & $\begin{array}{l}\text { (Phaseolus vulgaris/ } \\
\text { Colombia); } \mathrm{Sm}^{\mathrm{r}}\end{array}$ & $\begin{array}{l}\text { Martínez-Romero } \\
\text { et al. } 1991\end{array}$ \\
\hline 899-lpiA $\Delta 1$ & $\begin{array}{l}\text { CIAT } 899 \text { carrying a } 1173 \\
\text { bp-long nonpolar deletion } \\
\text { in lpiA; } \mathrm{Sm}^{\mathrm{r}} \text {; poor } \\
\text { competitor for bean nodule } \\
\text { occupancy }\end{array}$ & $\begin{array}{l}\text { Vinuesa et al. } \\
2003\end{array}$ \\
\hline \multicolumn{3}{|c|}{ Sinorhizobium meliloti } \\
\hline 1021 & SU47 str-21 & Meade et al. 1982 \\
\hline \multicolumn{3}{|c|}{ Pseudomonas aeruginosa } \\
\hline PAO1 & Wild type & $\begin{array}{l}\text { Holloway et al. } \\
1979\end{array}$ \\
\hline \multicolumn{3}{|l|}{ Escherichia coli } \\
\hline DH5 $\alpha$ & recA1, Ф80 lacZAM15 & Hanahan 1983 \\
\hline BL21(DE3)/pLysS & Expression strain & Studier et al. 1990 \\
\hline \multicolumn{3}{|l|}{ Plasmids } \\
\hline pBAD24 & $\begin{array}{l}\text { Expression vector, } \mathrm{Cb}^{\mathrm{r}} \text {, } \\
\text { arabinose-inducible }\end{array}$ & $\begin{array}{l}\text { Guzman et al. } \\
1995\end{array}$ \\
\hline pBADmprF & $\begin{array}{l}\text { S. aureus mprF cloned into } \\
\text { pBAD24 }\end{array}$ & Oku et al. 2004 \\
\hline pET9a & Expression vector, $\mathrm{Kan}^{\mathrm{r}}$ & Studier et al. 1990 \\
\hline pET16b & Expression vector, $\mathrm{Cb}^{\mathrm{r}}$ & Studier et al. 1990 \\
\hline $\mathrm{pET} 17 \mathrm{~b}$ & Expression vector, $\mathrm{Cb}^{\mathrm{r}}$ & Studier et al. 1990 \\
\hline pCCS49 & $\begin{array}{l}\text { R. tropici lpiA cloned as a } \\
\text { NdeI/KpnI fragment into } \\
\text { pET } 17 \mathrm{~b}\end{array}$ & This study \\
\hline pCCS51 & $\begin{array}{l}\text { B. subtilis mprF cloned as a } \\
\text { NcoI/BamHI fragment into } \\
\text { pET16b }\end{array}$ & Reeve et al. 2006 \\
\hline pBBR1-MCS5 & Broad-host-range plasmid & Kovach et al. 1995 \\
\hline pCCS 81 & $\begin{array}{l}\text { pET9a cloned as a BamHI } \\
\text { fragment into pBBR1- } \\
\text { MCS5 }\end{array}$ & This study \\
\hline pCCS57 & $\begin{array}{l}\text { pCCS51 cloned as a BamHI } \\
\text { fragment into pBBR1- } \\
\text { MCS5; } \mathrm{Gm}^{\mathrm{r}} ; \mathrm{Cb}^{\mathrm{r}}\end{array}$ & Reeve et al. 2006 \\
\hline pCCS76 & $\begin{array}{l}\text { pCCS } 49 \text { cloned as a } K p n I \\
\text { fragment into pBBR1- } \\
\text { MCS5; } \mathrm{Gm}^{\mathrm{r}} ; \mathrm{Cb}^{\mathrm{r}}\end{array}$ & This study \\
\hline
\end{tabular}

${ }^{\mathrm{a}} \mathrm{Sm}^{\mathrm{r}}, \mathrm{Cb}^{\mathrm{r}}, \mathrm{Kan}^{\mathrm{r}}, \mathrm{Gm}^{\mathrm{r}}$ = streptomycin-, carbenicillin-, kanamycin-, and gentamicin-resistant. subtilis (Reeve et al. 2006) and the lpiA gene from R. tropici were expressed in E. coli BL21(DE3)/pLysS under the control of the T7 promoter (Studier et al. 1990) from pCCS51 and pCCS49, respectively. As a positive control for LPG formation, we used the $S$. aureus $m p r F$ gene expressed in E. coli DH5 $\alpha$ under the control of the arabinose-inducible ara promoter (Guzman et al. 1995; Oku et al. 2004). For expression of $m p r F /$ lpiA homologs in Sinorhizobium meliloti, pCCS51, pCCS49, and pET9a were linearized with BamHI and were cloned into the BamHI site of pBBR1-MCS5, similarly to an earlier description (Gao et al. 2004).

\section{In vivo labeling of Escherichia coli strains expressing the $\mathrm{mprF} /$ lpiA homologs with $\left[{ }^{14} \mathrm{C}\right]$ acetate, $\left[{ }^{32} \mathrm{P}\right]$ phosphate, or $\left[{ }^{14} \mathrm{C}\right]$ lysine.}

For detection of LPG formation after overexpression of lpiA from $R$. tropici, $m p r F$ from B. subtilis, or $m p r F$ from $S$. aureus in $E$. coli, derivatives of strains BL21(DE3)/pLysS or DH5 $\alpha$ were cultivated in LB medium. At densities of $4 \times 10^{8}$ cells $/ \mathrm{ml}$, $0.1 \mathrm{mM}$ isopropyl- $\beta$-D-thiogalactoside or $1 \%$ L-arabinose (wt/vol) was added, and 1-ml aliquots were labeled in the presence of $1 \mu \mathrm{Ci}\left[1-{ }^{14} \mathrm{C}\right]$ acetate $(57 \mathrm{mCi} / \mathrm{mmol}$; Amersham, Piscataway, NJ, U.S.A.), $\left.1 \mu \mathrm{Ci} \mathrm{L-[U-}{ }^{14} \mathrm{C}\right]$ lysine $(304 \mathrm{mCi} / \mathrm{mmol}$; Amersham $)$, or $1 \mu \mathrm{Ci}\left[{ }^{32} \mathrm{P}\right]$ phosphate $(10 \mathrm{mCi} / \mathrm{ml}$; Amersham $)$ for $3 \mathrm{~h}$ at $37^{\circ} \mathrm{C}$. Subsequently, lipids were extracted and analyzed as described below.

\section{In vivo labeling of Rhizobium tropici and Sinorhizobium meliloti strains with $\left[{ }^{14} \mathrm{C}\right]$ acetate and $\left[{ }^{14} \mathrm{C}\right]$ lysine.}

The lipid compositions of Sinorhizobium meliloti and $R$. tropici strains were determined following labeling with [1${ }^{14} \mathrm{C}$ ]acetate $(57 \mathrm{mCi} / \mathrm{mmol}$; Amersham). Cultures $(1 \mathrm{ml})$ of wild type and mutant strains in TY medium (Beringer 1974) or minimal medium were inoculated from precultures grown in the same medium. After addition of $1 \mu \mathrm{Ci}\left[{ }^{14} \mathrm{C}\right]$ acetate to each culture, the cultures were incubated for $16 \mathrm{~h}$, in the case of $R$. tropici, and $8 \mathrm{~h}$, in the case of Sinorhizobium meliloti. In order to see whether lysine was preferentially incorporated into LPG, $R$. tropici was grown in modified Kenward minimal medium, which had been previously adjusted to $\mathrm{pH} 4.5$ as described above, and cultures were labeled with $\left[{ }^{14} \mathrm{C}\right]$ lysine for $8 \mathrm{~h}$.

The cells were harvested by centrifugation, were washed with $500 \mu \mathrm{l}$ of water, and were resuspended in $100 \mu \mathrm{l}$ of water. The lipids were extracted according to Bligh and Dyer (1959). The chloroform phase was used for lipid analysis on TLC plates (HPTLC aluminum sheets, silica gel 60; Merck, Hawthorne, NY, U.S.A.). After one-dimensional separation using the solvent system chloroform/methanol/glacial acetic acid, 130:50:20, or two-dimensional separation using the solvent systems described by de Rudder and associates (1997) (first dimension, chloroform/methanol/water, 140:60:10; second dimension, chloroform/methanol/glacial acetic acid, 130:50:20), the individual lipids were quantified. TLC plates were exposed to Kodak MXB film and the lipids were visualized by iodine staining. Quantification of the labeled lipids was done by scraping off the iodine-stained material and counting in scintillation vials with $3 \mathrm{ml}$ of nonaqueous scintillation fluid (Amersham). Alternatively, lipids were quantified using a Storm 820 phosphorimager (Molecular Dynamics, Sunnyvale, CA, U.S.A.), as described earlier (Sohlenkamp et al. 2004).

Isolation of bacteroids and labeling of bacteroid lipids.

Phaseolus vulgaris seeds were surface-sterilized with $1.2 \%$ sodium hypochlorite and were germinated on $1 \%$ water agar as described by Vinuesa and associates (1999). Seedlings were transferred to pots filled with vermiculite and a nitrogen-free 
nutrient solution (Fahraeus 1957) and were inoculated with about $10^{5}$ bacteria per plant. Plants were grown in a controlled growth chamber $\left(28^{\circ} \mathrm{C}, 12\right.$-h day and 12 -h night $)$ and were harvested 21 days postinoculation. Nodules were harvested and the bacteroids were isolated using a Percoll gradient centrifugation, essentially as described earlier (Romanov et al. 1994). Membrane lipids were extracted directly from bacteroids according to Bligh and Dyer (1959) when used for mass spectrometric investigations. The lipid mixture was analyzed using LC coupled to MS/MS for the presence of LPG.

\section{ESI-MS/MS analysis of rhizobial membrane lipids.}

Cultures $(500 \mathrm{ml})$ of Sinorhizobium meliloti 1021 harboring pCCS57, pCCS76, or pCCS81 were grown in TY medium to an optical density at $620 \mathrm{~nm}$ of 1.0 , and lipids were extracted according to a modified Bligh-and-Dyer procedure. Bacteroids were isolated from bean nodules as described above and lipids were isolated according to a modified Bligh-and-Dyer procedure.

All mass spectra were acquired on a QSTAR XL quadrupole time-of-flight mass spectrometer (ABI/MDS-Sciex, Toronto, Canada) equipped with a Triversa nanospray ionization source (Advion, Ithaca, NY, U.S.A.). Spectra were acquired in negative and positive ion mode and were the accumulation of 60 scans from $\mathrm{m} / \mathrm{z}, 200$ to 2,000. The nanospray (using Triversa system) MS settings were: nanospray voltage, $-1,100$ (negative ion mode) and $+1,200 \mathrm{~V}$ (positive ion mode); declustering potential, $55 \mathrm{~V}$; focusing potential, $265 \mathrm{~V}$.

Samples were diluted 1:100 or 1:1,000 in buffer A/buffer B (vol/vol, 1:1). The composition of buffer A was methanol/acetonitrile/1 $\mathrm{mM}$ ammonium acetate (vol/vol/vol, 60:20:20), and the composition of buffer B was $100 \%$ ethanol and $1 \mathrm{mM}$ ammonium acetate. Collision-induced dissociation tandem mass spectra were obtained using collision energy offsets of $-80 \mathrm{~V}$ (laboratory frame of reference) in the negative ion mode and $+50 \mathrm{~V}$ (laboratory frame of reference) in the positive ion mode. Nitrogen was used as the collision gas. Data acquisition and analysis were performed using Analyst QS software version 1.1.

\section{LC/MS/MS.}

LC/MS/MS analysis was performed using a Shimazu LC system (comprising a solvent degasser, two LC-10A pumps, and a SCL-10A system controller) coupled to a QSTAR XL quadrupole time-of-flight tandem mass spectrometer (as above). LC was operated at a flow rate of $200 \mu \mathrm{l} / \mathrm{min}$ with a linear gradient as follows: $100 \%$ A was held isocratically for $2 \mathrm{~min}$ and then linearly increased to $100 \%$ B over 14 min and held at $100 \%$ B for $4 \mathrm{~min}$. Mobile phase A consisted of methanol/acetonitrile/ aqueous $1 \mathrm{mM}$ ammonium acetate (60:20:20, vol/vol/vol). Mobile phase $\mathrm{B}$ consisted of $100 \%$ ethanol containing $1 \mathrm{mM}$ ammonium acetate. A Zorbax SB-C8 reversed-phase column (5 $\mu \mathrm{m}, 2.1 \times 50 \mathrm{~mm}$ ) was obtained from Agilent (Palo Alto, CA, U.S.A.). The post-column split diverted approximately $10 \%$ of the LC flow to the ESI source of the mass spectrometer. The MS settings were as follows: electrospray voltages, $+5,500 \mathrm{~V}$ (positive ion mode) and $-4,400 \mathrm{~V}$ (negative ion mode); declustering potential, $55 \mathrm{~V}$; focusing potential, $265 \mathrm{~V}$; nebulizer gas, $18 \mathrm{psi}$. The collision-induced dissociation tandem mass spectra were obtained with collision energy of $+52 \mathrm{~V}$ (laboratory frame of reference) in the positive ion mode or $-75 \mathrm{~V}$ (laboratory frame of reference) in the negative ion mode. Nitrogen was used as the collision gas.

\section{ACKNOWLEDGMENTS}

We are grateful to K. Kurokawa for sending us plasmids pBAD24 and pBADmprF. This research was supported by grants from CONACyT-
Mexico (46020-N and 42578-Q) and the Howard Hughes Medical Institute (HHMI 55003675). The mass spectrometry facility in the Department of Biochemistry of the Duke University Medical Center and Z. Guan were supported by the LIPID Metabolites And Pathways Strategy large-scale collaborative (grant number GM-069338 from the National Institutes of Health). J. Thomas-Oates and S. Robinson gratefully acknowledge funding from the Analytical Chemistry Trust Fund, the Royal Society of Chemistry Analytical Division, and the Engineering and Physical Sciences Research Council.

\section{LITERATURE CITED}

Beringer, J. E. 1974. R factor transfer in Rhizobium leguminosarum. J. Gen. Microbiol. 84:188-198.

Bligh, E. G., and Dyer, W. J. 1959. A rapid method of total lipid extraction and purification. Can. J. Biochem. Physiol. 37:911-917.

Comerci, D. J., Altabe, S., de Mendoza, D., and Ugalde, R. A.2006. Brucilla abortus synthesizes phosphatidylcholine from choline provided by the host. J. Bacteriol. 188:1929-1934.

Conde-Alvarez, R., Grilló, M. J., Salcedo, S. P., de Miguel, M. J., Fugier, E., Gorvel, J. P., Moriyón, I., and Iriarte, M. 2006. Synthesis of phosphatidylcholine, a typical eukaryotic phospholipid, is necessary for full virulence of the intracellular bacterial parasite Brucella abortus. Cel. Microbiol. 8:1322-1335.

Dandekar, T., Snel, B., Huynen, M., and Bork, P. 1998. Conservation of gene order: A fingerprint of proteins that physically interact. Trends Biochem. Sci. 23:324-328.

de Rudder, K. E. E., Thomas-Oates, J. E., and Geiger, O. 1997. Rhizobium meliloti mutants deficient in phospholipid $N$-methyltransferase still contain phosphatidylcholine. J. Bacteriol. 179:6921-6928.

de Rudder, K. E. E., Sohlenkamp, C., and Geiger, O. 1999. Plant-exuded choline is used for rhizobial membrane lipid biosynthesis by phosphatidylcholine synthase. J. Biol. Chem. 274:20011-20016.

de Rudder, K. E. E., López-Lara, I. M., and Geiger, O. 2000. Inactivation of the gene for phospholipid $\mathrm{N}$-methyltransferase in Sinorhizobium meliloti: Phosphatidylcholine is required for normal growth. Mol. Microbiol. 37:763-772.

Fahraeus, G. 1957. The infection of clover root hair by nodule bacteria studied by a single glass slide technique. J. Gen. Microbiol. 16:374381.

Fischer, W., and Leopold, K. 1999. Polar lipids of four listeria species containing L-lysylcardiolipin, a novel lipid structure, and other unique phospholipids. Int. J. Syst. Bacteriol. 49:653-662.

Gao, J. L., Weissenmayer, B., Taylor, A. M., Thomas-Oates, J. E., LópezLara, I. M., and Geiger, O. 2004. Identification of a gene required for the formation of lyso-ornithine lipid, an intermediate in the biosynthesis of ornithine-containing lipids. Mol. Microbiol. 53:1757-1770.

Geiger, O., Röhrs, V., Weissenmayer, B., Finan, T., and Thomas-Oates, J. E. 1999. The regulator gene phoB mediates phosphate stress-controlled synthesis of the membrane lipid diacylglyceryl- $N, N, N$-trimethylhomoserine in Rhizobium (Sinorhizobium) meliloti. Mol. Microbiol. 32:63-73.

Guzman, L. M., Belin, D., Carson, M. J., and Beckwith, J. 1995. Tight regulation, modulation and high-level expression by vectors containing the arabinose $\mathrm{P}_{\mathrm{BAD}}$ promoter. J. Bacteriol. 177:4121-4130.

Hanahan, D. 1983. Studies on transformation of Escherichia coli with plasmids. J. Mol. Biol. 166:557-580.

Holloway, B. W., Krishnapillai, V., and Morgan, A. F. 1979. Chromosomal genetics of Pseudomonas. Microbiol. Rev. 43:73-102.

Houtsmuller, U. M., and van Deenen, L. L. M. 1963. Identification of a bacterial phospholipid as an $O$-ornithine ester of phosphatidylglycerol. Biochim. Biophys. Acta 70:211-213.

Houtsmuller, U. M., and van Deenen, L. L. M. 1964. On the accumulation of amino acid derivatives of phosphatidylglycerol in bacteria. Biochim. Biophys. Acta 84:96-98.

Kawai, F., Shoda, M., Harashima, R., Sadaie, Y., Hara, H., and Matsumoto, K. 2004. Cardiolipin domains in Bacillus subtilis marburg membranes J. Bacteriol. 186:1475-1483.

Kenward, M. A., Brown, M. R. W., and Fryer, J. J. 1979. The influence of calcium or manganese on the resistance to EDTA, polymyxin B or cold shock, and the composition of Pseudomonas aeruginosa grown in glucose-or magnesium-depleted batch cultures. J. Appl. Bacteriol. 47:489503.

Kovach, M. E., Elzer, P. H., Hill, S. E., Robertson, G. T., Farris, M. A., Roop II, R. M., and Peterson, K. M. 1995. Four new derivatives of the broad-host-range cloning vector pBBR1MCS, carrying different antibiotic resistance cassettes. Gene 166:175-176.

Lang, D. R., and Lundgren, D. E. 1970. Lipid composition of Bacillus subtilis during growth and sporulation. J. Bacteriol. 101:483-489.

Lee, V. T., and Schneewind, O. 2001. Protein secretion and the pathogene- 
sis of bacterial infections. Genes Dev. 15:1725-1752.

López-Lara, I. M., Sohlenkamp, C., and Geiger, O. 2003. Membrane lipids in plant-associated bacteria: Their biosyntheses and possible functions. Mol. Plant-Microbe Interact. 16:567-579.

López-Lara, I. M., Gao, J.-L., Soto, M. J., Solares-Péres, A., Weissenmayer, B., Sohlenkamp, C., Verroios, G. P., Thomas-Oates, J., and Geiger, O. 2005. Phosphorus-free membrane lipids of Sinorhizobium meliloti are not required for the symbiosis with alfalfa but contribute to increased cell yields under phosphorus-limiting conditions of growth. Mol. PlantMicrobe Interact. 18:973-982.

MacFarlane, M. G. 1961. Characterization of lipo-aminoacids as $O$-amino acid esters of phosphatidylglycerol. Nature 196:136-138.

Martínez-Romero, E., Segovia, L., Mercante, F. M., Franco, A. A., Graham, P., and Pardo, M. A. 1991. Rhizobium tropici, a novel species nodulating Phaseolus vulgaris L. beans and Leucaena sp. trees. Int. J. Syst. Bacteriol. 41:417-426.

Meade, H. M., Long, S. R., Ruvkun, G. B., Brown, S. E., and Ausubel, F M. 1982. Physical and genetic characterization of symbiotic and auxotrophic mutants of Rhizobium meliloti induced by transposon Tn5 mutagenesis. J. Bacteriol. 149:114-122.

Minder, A. C., de Rudder, K. E. E., Narberhaus, F., Fischer, H.-M., Hennecke, H., and Geiger, O. 2001. Phosphatidylcholine levels in Bradyrhizobium japonicum are critical for an efficient symbiosis with the soybean host plant. Mol. Microbiol. 39:1186-1198.

Nahaie, M. R., Goodfellow, M., Minnikin, D. E., and Hajek, V. 1984. Polar lipid and isoprenoid quinone composition in the classification of Staphylococcus. J. Gen. Microbiol. 130:2427-2437.

Nishi, H., Komatsuzawa, H., Fujiwara, T., McCallum, N., and Sugai, M 2004. Reduced content of lysyl-phosphatidylglycerol in the cytoplasmic membrane affects susceptibility to moenomycin, as well as vancomycin, gentamicin, and antimicrobial peptides, in Staphylococcus aureus. Antimicrob. Agents Chemotherap. 48:4800-4807.

Oku, Y., Kurokawa, K., Ichihashi, N., and Sekimuzu, K. 2004. Characterization of the Staphylococcus aureus mprF gene, involved in lysinylation of phosphatidylglycerol. Microbiology 150:45-51.

O’Leary, W. M., and Wilkinson, S. G. 1988. Gram-positive bacteria. Pages 117-201 in: Microbial Lipids. C. Ratledge and S. G. Wilkinson, eds. Academic Press, London.

Op den Kamp, J. A., Redai, I., and van Deenen, L. L. 1969. Phospholipid composition of Bacillus subtilis. J. Bacteriol. 99:298-303.

Overbeek, R., Fonstein, M., D’Souza, M., Pusch, G. D., and Maltsev, N. 1999. The use of gene clusters to infer functional coupling. Proc. Natl. Acad. Sci. U.S.A. 96:2896-2901.

Pantoja, M., Chen, L., Chen, Y., and Nester, E. W. 2002. Agrobacterium type IV secretion is two-step process in which export substrates associate with the virulence protein VirJ in the periplasm. Mol. Microbiol. 45:1325-1335.

Peschel, A., Jack, R. W., Otto, M., Collins, V. L., Staubitz, P., Nicholson, G., Kalbacher, H., Nieuwenhuizen, W. F., Jung, G., Tarkowski, A., van Kessel, K. P. M., and van Strijp, J. A. G. 2001. Staphylococcus aureus resistance to human defensins and evasion of neutrophil killing via the novel virulence factor $\mathrm{MprF}$ is based on modification of membrane lipids with L-Lysine. J. Exp. Med. 193:1067-1076.
Raetz C. R. H., and Whitfield, C. 2002. Lipopolysaccharide endotoxins. Annu. Rev. Biochem. 71:635-700.

Reeve, W. G., Tiwari, R. P., Worsley, P.S., Dilworth, M. J., Glenn, A. R., and Howieson, J. G. 1999. Constructs for insertional mutagenesis, transcriptional signal localisation and gene regulation studies in root nodule and other bacteria. Microbiology 145:1307-1316.

Reeve, W. G., Tiwari, R. P., Bräu, L., Castelli, J., Garau, G., Dilworth, M. J., Sohlenkamp, C., Geiger, O., Glenn, A. R., and Howieson, J. G. 2006. The Sinorhizobium medicae WSM419 lpiA gene is transcriptionally activated by low $\mathrm{pH}$ and regulated by FsrR. Microbiology 152:3049-3059.

Rojas-Jiménez, K., Sohlenkamp, C., Geiger, O., Werner, D., MartínezRomero, E., and Vinuesa, P. 2005. A putative $\mathrm{ClC}$ chloride channel homolog and ornithine-containing membrane lipids of Rhizobium tropici CIAT899 are involved in symbiotic efficiency and acid tolerance. Mol. Plant-Microbe Interact. 18:1175-1185.

Romanov, V. I., Hernandez-Lucas, I., and Martinez-Romero, E. 1994. Carbon metabolism enzymes of Rhizobium tropici cultures and bacteroids. Appl. Environ. Microbiol. 60:2339-2342.

Ruvkun, G. B., and Ausubel, F. M. 1981. A general method for site-directed mutagenesis in prokaryotes. Nature 289:85-88.

Sambrook, J., and Russell, D. R. 2001. Molecular Cloning: A Laboratory Manual. Cold Spring Harbor Press, Cold Spring Harbor, NY, U.S.A.

Sohlenkamp, C., de Rudder, K. E. E., Röhrs, V., López-Lara, I. M., and Geiger, O. 2000. Cloning and characterization of the gene for phosphatidylcholine synthase. J. Biol. Chem. 275:18919-18925.

Sohlenkamp, C., López-Lara, I. M., and Geiger, O. 2003. Biosynthesis of phosphatidylcholine in bacteria. Prog. Lipid Res. 42:115-162.

Sohlenkamp, C., de Rudder, K. E. E, and Geiger, O. 2004. Phosphatidylethanolamine is not essential for growth of Sinorhizobium meliloti on complex culture media. J. Bacteriol. 186:1667-1677.

Staubitz, P., Neumann, H., Schneider, T., Wiedemann, L., and Peschel, A. 2004. MprF-mediated biosynthesis of lysylphosphatidylglycerol, an important determinant in staphylococcal defensin resistance. FEMS (Fed. Eur. Microbiol. Soc.) Microbiol. Lett. 231:67-71.

Studier, F.W., Rosenberg, A. H., Dunn, J. J., and Dubendorff, J. W. 1990 Use of T7 RNA polymerase to direct expression of cloned genes. Methods Enzymol. 185:60-89.

Udvardi, M. K., and Day, D. A. 1997. Metabolite transport across symbiotic membranes of legume nodules. Annu. Rev. Plant Physiol. Plant Mol. Biol. 48:493-523.

Udvardi, M. K., Lister, D. L., and Day, D. A. 1991. ATPase activity and anion transport across the peribacteroid membrane of isolated soybean symbiosomes. Arch. Microbiol. 156:362-366.

Vinuesa, P., Reuhs, B. L., Breton, C., and Werner, D. 1999. Identification of a plasmid-borne locus in Rhizobium etli KIM5s involved in lipopolysaccharide O-chain biosynthesis and nodulation of Phaseolus vulgaris. J. Bacteriol. 181:5606-5614.

Vinuesa, P., Neumann-Silkow, F., Pacios-Bras, C., Spaink, H. P., MartinezRomero, E., and Werner, D. 2003. Genetic analysis of a pH-regulated operon from Rhizobium tropici CIAT899 involved in acid tolerance an nodulation competitiveness. Mol. Plant-Microbe Interact. 16:159-168.

Werner, D., Wilcockson, J., and Zimmermann, E. 1975. Adsorption and selection of rhizobia on ion-exchange papers. Arch. Microbiol. 105:27-32. 